\title{
RUMO A UMA NOVA ORDEM GLOBAL Vinte anos após 1989 e além
}

\section{Hauke Brunkhorst}

\author{
Tradução de Sebastião Nascimento
}

Não há dúvida de que o ano de 1989 levou a uma transformação maciça (Michael Geyer) não somente da Alemanha e do que fora o Império Soviético, mas de toda a ordem internacional e global. Mas que tipo de transformação? Foi, por exemplo, revolucionária, como sugere Konrad Jarausch? Isso é defensável, mas depende muito da definição de "revolução" que se adote. Se não quisermos inflar demais o termo, seria prudente atermo-nos aos casos paradigmáticos das Revoluçóes Francesa e Americana. Se tais revoluçóes ainda guardam essa dimensão paradigmática, então uma verdadeira revolução pressupõe (entre outras coisas):

- Primeiro, que exista uma nova ideia de liberdade, que denote um novo sentido normativo para esse vetusto vocábulo e mais, essa ideia deveria se encaixar numa lógica evolutiva em ao menos duas dimensões: que a nova ideia (1) revele uma nova categoria (ou dimensão) de liberdade (por exemplo, liberdade individual, oposta à liberdade corporativa; autodeterminação, distinta da não dominação); (2) seja mais inclusiva que ideias anteriores de liberdade (por exemplo, dos direitos da nobreza aos direitos do cidadão, da democracia burguesa à democracia de massas, dos direitos humanos nacionais aos direitos humanos universais). ${ }^{1}$ Contudo, para que seja de fato revolucionária, uma ideia necessita muito mais, a saber,

- segundo, um conjunto de duradouras concretizaçōes institucionais e realizaçôes sociais dessa nova ideia de liberdade. Em outras palavras, junto à nova ideia de liberdade, deve haver um novo desenho institucional ou um novo tipo de direito constitucional, como foi o caso no período da Reforma Protestante Alemã, quando todos os poderes legislativos e judiciários foram concentrados nas mãos do governante secular, ou na Revolução Inglesa, quando Cromwell, 
pela primeira vez na história, criou a legislação parlamentar, ou nas Revoluçôes Francesa e Alemã, quando foi experimentada a altamente improvável combinação da autolegislação popular com um direito constitucional fundante da divisão de poderes, e o Terceiro Estado foi reintroduzido sob a forma de Assembleia Nacional.

Que ambos os pressupostos surjam simultaneamente - uma nova ideia de liberdade $e$ uma nova (e funcional) configuração constitucional - é algo extremamente improvável em termos históricos e, portanto, acontece muito raramente. Mesmo que 1989 tenha sido improvável, e particularmente improvável que os tanques se tenham mantido nos quartéis, mesmo que tenha sido uma transformação maciça de baixo pra cima e da ditadura para a liberdade e a democracia, mesmo que tenha "mudado o mapa" (Jarausch) e toda a sociedade mundial, não havia qualquer ideia nova e poderosa, nem de liberdade, nem de direito constitucional, com a única e importante, mas isolada, exceção das mesas-redondas. O uso mais inovador desse método ocorreu (e ainda ocorre) durante o processo de transformação pacifica, para desempenhar o papel jurídico específico e limitado de reprocessamento do passado (Aufarbeitung der Vergangenheit). Por isso é que foi tão fácil para os tecnocratas ocidentais negligenciá-lo quando se tratou de reelaborar a constituição ou de elaborar constitucionalmente a anexação dos novos Estados federativos à esfera constitucional da República Federal Alemã.

Apesar disso, os eventos de 1989 representaram - e esta é minha tese central - o estágio final e conclusivo de uma transformação revolucionária mais ampla, viabilizada por cem anos de movimento operário, por inúmeros levantes sociais e, especialmente, por duas guerras mundiais, travadas não apenas em razão de interesses nacionais, imperiais e de autopreservação, mas também na busca de objetivos revolucionários, em nome da humanidade (tão frequentemente invocada em sentidos abusivos), assim como da democracia e do socialismo, travadas como guerras "que cessariam todas as guerras" (Wilson) e para erigir um "mundo unificado" (One World, na expressão de Roosevelt), onde a "democracia est[ivesse] em segurança” (Wilson). As novas ideias de liberdade (I) que surgiram naquele período abrangiam, pela primeira vez, (1) direitos humanos universais declarados sob forma jurídica, (2) a exclusão universal da desigualdade como um princípio jurídico válido de direito internacional, ${ }^{2}$ estreitamente ligados à (3) própria virada revolucionária do direito internacional, de um direito de coexistência para um direito de cooperação, assim como, ademais, (4) a autodeterminação universal e o assistencialismo internacional que precederam imediatamente os programas nacionais voltados à busca igualitária da felicidade. ${ }^{3}$ Esses programas foram implementados por (II) um novo tipo de direito constitucional, que incluía (1) a programação conclusiva de regimes abrangentes de assistência social, (2) um longo período de democracia de massas inclusiva e experimental, (3) uma revolução juridica permanente assentada nos direitos que rapidamente transcenderam a base inicial racial (branca) da ação afirmativa, ${ }^{4}(4)$ um novo sistema de direito internacional pós-westfaliano ou, melhor, pós-equilíbrio de poder (e pós-coexistência pacífica) e (5) a fundação de um novo sistema de instituições internacionais que perduraram e que, em poucas décadas, acabaram por se tornar uma rede sempre mais densa de organizações inter, trans e supranacionais.

O icônico evento da queda do muro seguiu o rastro dessas invenções revolucionárias e, por fim, foi viabilizado por elas. Não foi o início de algo novo, tampouco foi, como Habermas e Furet sugeriram, tão somente uma revolução retardada (Habermas), uma revolução simulada, destinada a implementar os princípios esquecidos, reprimidos e violados de 1789 . Na verdade, foi a conclusão das mudanças revolucionárias do século XX. Conclusão, nesse caso, que coincide com a globalização da ordem institucional básica da até então rudimentar integração normativa da sociedade mundial. Em termos hegelianos, a sociedade mundial era, até 1989, uma sociedade normativamente integrada em si mesma e, desde então, é uma sociedade mundial normativamente integrada em e para si mesma.

- Foi somente a partir de 1989 que a rede de instituiçôes internacionais passou a cobrir todo o globo e a não mais se deter diante da cortina de ferro. Até a China segue agora o regime de direito brando (soft law) da OMC (de forma mais ou 
menos relutante, mas a questão é: cooperação, para bem ou para mal, tornou-se inevitável). Até mesmo a Rússia de Putin é afetada pelas decisões da Corte Europeia de Direitos Humanos. Nem mesmo o Irã pode se furtar à cooperação internacional, à qual se obrigou ao firmar o Tratado de Não-Proliferação Nuclear. Esse é um caso interessante, pois o tratado permite que qualquer parte o denuncie, mas isso acabaria sendo interpretado - corretamente, aliás - como uma violação do princípio de cooperação.

- $\quad \mathrm{O}$ ano de 1989 viabilizou a conclusão da fase pós-imperial de construção estatal. Após a descolonização dos anos de 1950 e 1960, a dessovietização do mundo nos anos de 1990 foi a segunda e última etapa no caminho que levava do imperialismo a um sistema global de Estados nacionais iguais sob o direito internacional (art. 2 I da Carta da ONU). Esse processo de descolonização universal em dois estágios já havia sido planejado no final da Segunda Guerra Mundial e surgia como uma implicação direta do novo direito internacional (art.1 II da Carta), tendo sido concluído somente após o fim do Império da União Soviética. Somente então é que até o último metro quadrado de massa continental pôde se tornar território estatal; consequência imediata disso foi que, a partir de então, o problema dos Estados falidos diria respeito a toda a comunidade internacional.

- O novo sistema de direito internacional pós-Segunda Guerra Mundial foi finalmente globalizado. O caso de Andrei Sakharov foi o ponto de virada depois do qual o célebre $S$ r. Não (Mr. Nyet), Andrei Gromyko, passou a ser visto como uma figura muito mais obsoleta do que já era em seu tempo. Somente então é que cessou a coexistência pacífica e a absoluta não interferência para além das fronteiras do Império (ou área de influência), assim como a cooperação e a ajuda fraternal destinadas unicamente aos bons camaradas em Budapeste e Praga. A diferença entre moralidade imperial interna e externa ruiu; também os norte-americanos tiveram de passar pela mesma experiência no caso de Guantánamo, após o que o juiz Antonin Scalia não mais poderá defender o esplêndido isolamento da Corte Suprema dos Estados Unido sem relação a qualquer possibilidade de acesso ao direito internacional. ${ }^{5}$

- A conclusão do processo de constitucionalização democrática durante a década de 1990 esvaziou qualquer alternativa séria à democracia, ao menos nos manuais de direito constitucional. A China e o Irã ainda representam importantes exceções. O Irã é uma teocracia constitucional (em grande medida comparável com as monarquias constitucionais da Europa do século XIX) e a China tem uma constituição democrática (seguindo o modelo da Constituição dos Estados Unidos), mas com prerrogativas mais ou menos irrestritas para o Partido Comunista (a despeito de terem havido algumas reformas importantes recentemente, sobretudo na direção do reconhecimento de direitos de propriedade $e$ de direitos humanos, ao menos simbolicamente. ${ }^{6}$

- O público e a sociedade civil mundiais tornaram-se, imediatamente após 1989, globais. O acesso aos meios globais de disseminação de informação não mais cessa em Dresden, e a rede global de ONGs (as associações livres toquevillianas que povoam o seio de qualquer sociedade civil) não mais se detém nas fronteiras da China, do Irã ou da Rússia. Agora, existe um público mundial e uma sociedade civil global, ainda que sejam muito mais vulneráveis ao poder social e político (desigualmente distribuído e insuficientemente democrático), o que explica em parte a forte guinada dos Estados recém-fundados para a extrema direita. ${ }^{7}$

- Por último, mas não menos importante, o capitalismo moderno (juntamente com todos os sistemas sociais funcionalmente diferenciados) tornou-se global e não enfrenta hoje qualquer alternativa externa.

Contudo, no momento de seu mais incontrastável triunfo, a democracia passa a ser pressionada. A nova ordem mundial pode ser (e, de fato, foi), com razão, descrita como uma ordem constitucional. Mas o processo de constitucionalização não deve ser confundido com democratização. Isso consiste numa ilusão europeia e, especialmente, numa ilusão 
de juristas e teóricos políticos alemães, ademais de ser a ideologia dos líderes das União Europeia e de seu maquinário de propaganda intelectual. A ilusão consiste na ideia de que a juridicização e o Estado de direito automaticamente conduzem à democracia. São reveladores tanto o nome como a configuração da consideravelmente influente Comissão de Veneza do Conselho da Europa, que desempenhou um importante papel no processo de constitucionalização no Leste Europeu, atuando por vezes como uma espécie de poder constituinte internacional:8 "Comissão Europeia para a Democracia através do Direito". Mas o que é constitutivo da crise de legitimação da União Europeia, ${ }^{9}$ vale lembrar, é que existe apenas um caminho para a democracia através do direito, e é o que leva ao direito através da democracia. Juridicização e constitucionalização não são a solução do problema da democracia europeia e cosmopolita, mas parte do problema. $\mathrm{O}$ dilema constitucional da atual sociedade mundial consiste no fato de que a ilusão complementar, compartilhada por alguns norte-americanos e pela Câmara de Lisboa da Corte Constitucional Alemã, é ainda pior, apoiando-se na ilusão de que a democracia está assegurada no interior das fronteiras do Estado nacional e pode ser salva se ali se mantiver. A razão é simples. A juridicização e a constitucionalização da sociedade mundial são irreversíveis e viabilizam (como tem sido o caso desde a primeira grande onda de juridicização da política, após a Revolução Papal do século XII) algum avanço do Estado de direito (o que não é pouco), mas um avanço ainda maior na estabilização das relações não democráticas de dominação vigentes. Contudo, como podemos ver claramente no caso de todos os regimes neonacionais, toda regressão para aquém do nível do direito e da política pós-nacionais é um passo numa direção que usualmente culmina em algum tipo de regime fascista.

O novo e consideravelmente fragmentado sistema constitucional da sociedade mundial inclui o poder administrativo do sistema de Estados, mas está longe de retomar o controle do capitalismo sistêmico global, que se transformou, de confortável sistema de mercados assentados no Estado do capitalismo tardio (quando Nixon dizia: "Somos todos keynesianos"), no profundamente desconfortável sistema de Estados assentados no mercado do turbo- capitalismo global. Ao que tudo indica, parece que, desde 1989, quando o Estado nacional democrático alcançou todo o globo, o capitalismo triunfou sobre a democracia. E mesmo ali onde esta era bem-sucedida, regrediu ao formato da "democracia de baixa intensidade" (Susan Marks) dos mercados e eleições livres, não apenas no Leste Europeu, mas também nos países ocidentais.

O experimentalismo democrático de massas, a crescente inclusão social, política e cultural e o espírito utópico do igualitarismo e da autotranscendência democráticos, que forjaram o desenvolvimento democrático a partir da década de 1940 e a revolução global dos direitos da década de 1960 e que ainda se encontram corporificados em todos os nossos textos constitucionais, desapareceram rapidamente após 1989. A tecnocrática reunificação alemã (que tratou invenções constitucionais como minutas de mesas redondas de uma política amadora e o poder constituinte como digno apenas de uso por meio de manipulação extraconstitucional) foi apenas o início de um processo de longo prazo, que levou à reemergência de um tedioso (e profundamente irrealista) realismo internacional: um renascimento de teorias schumpeterianas elitistas de democracia (acompanhadas, na Alemanha, por uma teoria política afirmativa da nova liderança burguesa [neue Bürgerlichkeit] e por uma propaganda cultural nietzscheana de direita a respeito da desigualdade estrutural das pessoas (Sloterdijk); o triunfo da soberania estatal sobre a soberania popular, finalmente entronado na profundamente paroquial sentença da Corte Constitucional Alemã sobre o Tratado de Lisboa; ${ }^{10}$ a celebração da governança sem governo democrático nos memorandos da Comissão Europeia e na ciência política; ou, na filosofia política, a substituição da autolegislação igualitária pela velha e pobre ideia republicana de liberdade como não dominação. Por trás dessa "enorme superestrutura" (Marx), floresce uma nova estrutura de base, que consiste substancialmente na introdução de regimes regionais e globais de direito brando com força vinculante de fato, que passam ao largo de controles parlamentares ou judiciais. O resultado desses processos é a emergência e a estabilização de uma nova classe dominante econômico-politico-especializada, que, pela primeira vez na história, é realmente transna- 
cional. O sonho do cosmopolitismo, expresso pela imagem icônica da queda do muro, foi realizado como o cosmopolitismo de poucos (Craig Calhoun). A imagem da atual sociedade mundial, como bem notou Slavoj Zizek no New York Times de 9 de novembro de 2009, "aproxima-se assustadoramente da mais exagerada imagem esquerdista do capitalismo: uma sociedade na qual a democracia formal meramente encobre o domínio de uma maioria abastada”.

\section{$* * *$}

E com Barack Obama? A integração do público global à sua campanha indica que políticos e tecnocratas elitistas têm de se confrontar com um alto risco interno, qual seja, o de uma verdadeira crise de legitimação. A retórica importa e é significativo que Obama, em sua bem-sucedida campanha, tenha repetidamente invocado o espírito da democracia radical, utilizando os termos da $11^{\mathrm{a}}$ tese contra Feuerbach: "Somos os que mudamos o mundo". O espírito da democracia radical ainda está vivo e pode tornar manifesta a latente crise de legitimação da democracia de baixa intensidade, ainda que a reforma do sistema de saúde mostre o quão difícil é ampliar a solidariedade democrática numa sociedade que já excluiu um quarto ou mais de sua população de qualquer acesso à participação democrática ou a direitos de assistência social (e a Europa não é muito melhor nesse aspecto). Não é uma questão que revolva em torno da figura weberiana do manobrista de novas ideias. Elas já estão "em curso" (Hegel) desde o fim da pior guerra da história. Após a derrocada da socialdemocracia, porém, e com o esmaecimento do movimento operário, não há qualquer poder efetivo no horizonte que possa organizar os interesses que poderiam mudar a história e o curso da sociedade mundial, já que a tão incensada multidão, por definição, é incapaz de transformar o que quer que seja. E este é o problema: um capitalismo que é global e um sistema altamente produtivo, mas internamente catastrófico, que não precisa da democracia e para o qual não existe hoje qualquer alternativa.

\section{Notas}

1 Exemplos históricos são as Declarações de 1776 e 1789 ou os dois primeiros artigos da Carta da ONU, de 1945, e a Declaração Universal dos Direitos Humanos, de 1948, ou, muito antes, a "Liberdade de um cristão", de Lutero, de 1520, e o terceiro dos Treze Artigos da Confederação dos Camponeses, de 1522, que estipula simplesmente "que somos livres e queremos ser livres", ou ainda a Lei do Habeas Corpus, de 1679, e a Carta de Direitos (Bill of Rights), de 1689.

2 Sobre o termo direito mundial (World Law), ver Berman (1994).

3 Franklin D. Roosevelts, "Second Bill of Rights from 1944”. Ver Sunstein (2004).

4 Katznelson (2005).

5 Sobre o último, ver Rainer Nickel (2009).

6 O desenvolvimento do socialismo soviético foi muito diferente do que ocorreu na China, o que pode ser explicado por duas causas. Primeiro, após a era totalitária do stalinismo, foram feitos grandes esforços para reformar o socialismo sob Kruchtchev e novamente sob Brejnev, mas nem juridicamente, nem economicamente foram bem-sucedidos em estabelecer o Estado de direito e um verdadeiro socialismo de consumo. Depois que os tanques invadiram Praga para manter sob controle o socialismo com face humana, os últimos recursos de um já reduzido capital de legitimidade foram esgotados. Isso tornou o regime completamente incapaz de se reformar, daí a primeira tentativa de reforma, sob Gorbatchev, ter sido o primeiro passo para o abismo. Devido ao fato de que sequer a nomenklatura comunista acreditava mais no socialismo soviético, todas as alternativas se haviam reduzido a duas: tanques ou mudança de regime e sistema. Completamente diferente do que ocorreu na China, onde a transformação do comunismo autoritário de partido único, iniciada imediatamente após a era totalitária, ainda contava com uma capa mais densa de crença em sua legitimidade e pôde ser apresentada como um movimento rumo ao capitalismo autoritário, que já possuíam uma longa e parcialmente bem-sucedida tradição no Ocidente (de Luís Bonaparte, passando por Mussolini e Hitler, até Pinochet) e, em especial, no Extremo Oriente (Japão).

7 Um dos efeitos mais marcantes da rápida emergência de um público global após 1989 teve uma dimensão psicológica e consistiu numa abrangente universalização e no completo descentramento do racionalismo ocidental, o que levou a uma percepção generalizada 
de que o racionalismo não era mais ocidental e que, portanto, poderia (e imediatamente passou a) ser interpretado a partir de perspectivas sociais, regionais e culturais amplamente diversas. Assim, a modernidade, que por muito tempo parecia constituir uma exceção europeia (e americana), pluralizou-se em múltiplas, mas emaranhadas, modernidades. Não obstante, é preciso ter em mente que, no mais tardar a partir de 1989 , com o fim da profundamente artificial auto-exclusão do socialismo autoritário e imperial, passou a existir uma única cultural racional mundial e uma única sociedade mundial. Isso não minimiza, porém, as diferenças sociais $e$ culturais internas e mesmo estruturais, as tensōes e as contradiçôes da sociedade mundial, mas, pelo contrário, maximiza-as, criando permanentemente novas modalidades e fazendo com que suas tensōes explodam.

8 Sobre o conceito, com exemplos mais eloquentes, ver Dann e Al-Ali (2006). Sobre a Comissão de Veneza, ver Nickel (2009).

9 Brunkhorst, Hauke (2008).

10 Ver Daniel Halberstam e Christoph Moellers (2009); Christoph Schoenberger (2009); Arnim von Bogdandy (2009).

\section{BIBLIOGRAFIA}

BERMAN, Harold J. (1994-1995), "World Law", 18 Fordham International Law Journal 1617.

BOGDANDY, Arnim von. (2009), "Prinzipien der Rechtsfortbildung im Europaeischen Rechtsraum. Ueberlegungen zum Lissabon-Urteil des Bundesverfassungsgerichts und gegen den methodischen Nationalismus". Manuscrito inédito.

BRUNKHORST, Hauke. (2008), "State and constitutions: a reply to Scheuerman”. Constellations, 15 (4): 493-501.

DANN, Phillip \& Al-Ali, Zaid. (s. d.), "The internationalized Pouvoir Constituant - Constitution-Making under external influence in Iraq, Sudan and East Timor". Max Planck Yearbook of United Nations Law 10, pp. 423-463.

HALBERSTAM, Daniel \& MOELLERS, Christoph. (2009), "The German Constitutional Court says Ja zu Deutschland". German Law Review, 8.
KATZNELSON, Ira. (2005), When affirmative action was white. Nova York/Londres, W. W. Norton.

NICKEL, Rainer. (2009), "Transnational borrowing among judges: towards a common core of European and global constitutional law?", in (ed.). Conflicts of law and laws of conflict in Europe and beyond, Oslo, Arena. pp. 281-306.

SCHOENBERGER, Christoph. (2009), "Lisbon in Karlsruhe: Maastricht's Epigones At See". German Law Review, 8.

SUNSTEIN, Cass. (2004), The Second Bill of Rights. Nova York, Basic Books. 